\title{
OPTIMIZATION OF A HPLC PROCEDURE FOR SIMULTANEOUS DETERMINATION OF CISPLATIN AND THE COMPLEX CIS,CIS,TRANS-DIAMMINEDICHLORODIHYDROXOPLATINUM(IV) IN AQUEOUS SOLUTIONS
}

\author{
Yalexmi Ramos*, Carlos Hernández, Lidia Asela Fernandez, Mayra Bataller y Eliet Veliz \\ Ozone Research Center, National Center for Scientific Research, Havana, Cuba \\ Renny Small \\ Laboratories MEDSOL, Havana, Cuba
}

Recebido em 10/9/10; aceito em 1/3/11; publicado na web em 5/5/11

\begin{abstract}
A RP-HPLC procedure for the simultaneous determination of cisplatin and the complex cis,cis,trans-diamminedichlorodihydroxoplatinum(IV), was development. The developed procedure was validated in terms of linearity, accuracy, precision, limits of detection (LOD), limits of quantification (LOQ) and specificity. The limits of detection (LOD) were $0.47 \times 10^{-4}$ and $0.53 \times 10^{-4} \mathrm{~mol} \mathrm{~L}^{-1}$ and the limits of quantification (LOQ) were $1.57 \times 10^{-4}$ and $1.75 \times 10^{-4} \mathrm{~mol} \mathrm{~L}^{-1}$, for cisplatin and cis,cis,trans-diamminedichlorodihydroxoplatinum(IV), respectively. The average recoveries of cisplatin and cis,cis,trans-diamminedichlorodihydroxoplatinum(IV) was $100.6 \%$ \pm 1.4 and $101.2 \% \pm 1.1$, respectively. Intermediate (inter-day) precision, repeatability and specificity of the procedure for hydrolysis products of cisplatin were studied. The results of the study showed that the proposed RP-HPLC procedure is simple, rapid, precise, accurate and specific.
\end{abstract}

Keywords: cisplatin; cis,cis,trans-diamminedichlorodihydroxoplatinum(IV); analytical validation.

\section{INTRODUCTION}

Cisplatin, cis-diamminedichloroplatinum(II) is an inorganic coordination compound, commonly used in the treatment of different solid tumors. However, it is also highly toxic and probable carcinogenic in humans. ${ }^{1}$ The presence of cisplatin in waters and wastewaters has been reported. The excretion via faeces and urine of patients under medical treatment and disposal of unused pharmaceuticals, ${ }^{2-4}$ effluents from hospitals ${ }^{5-8}$ and wastewaters generated during the pharmaceutical manufacturing process, ${ }^{9}$ represent the major contamination sources for this cytostatic.

In many cases, cisplatin is discharged into receiving waters due to their incomplete removal in sewage treatment plants (STPs). ${ }^{5,7,8}$ Therefore, more effective technologies such as ozonation should be employed. The ozonation of cisplatin at $\mathrm{pH} 9$ in non-buffered aqueous solutions was recently reported by Hernández et al.. ${ }^{10}$ In this study, a rapid elimination of cisplatin $(99.3 \%$ conversion in about 2 min of reaction time) with the corresponding formation of non-mutagenic complex cis,cis,trans-diamminedichlorodihydroxoplatinum(IV), were obtained (Figure 1).

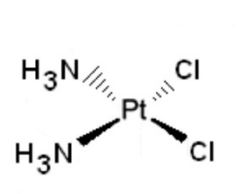

1

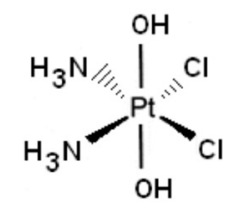

2
Figure 1. Chemical structures of the complexes cisplatin (1) and cis, cis, transdiamminedichlorodihydroxoplatinum(IV)

*e-mail: yalexmi.ramos@cnic.edu.cu
For the simultaneous determination of both complexes a reversed-phase HPLC on an RP18 LiChroCART (250 x 4 mm ID, $5 \mu \mathrm{m}$ particle size) column was employed. In this case the composition of the mobile phase was similar to the one reported by El-Khateeb et $a l .{ }^{11}$ for the study of cisplatin and its hydrolysis products, except that "triflic acid" was substituted by methanesulphonic acid, and sodium dodecyl sulphate (SDS) concentration was one tenth of the one used by those authors. Under these chromatographic conditions cisplatin eluted at $2.1 \mathrm{~min}$ but the complex cis,cis,trans-diamminedichlorodihydroxoplatinum(IV) had a very long retention time (16.5 min) and appeared as a broad peak. Another disadvantage of the method is that with more rapid throughput of samples, there was some variation in the retention time for the complex cis,cis,trans-diamminedichlorod ihydroxoplatinum(IV) and its elution in term of retention time was not reproducible. A similar shift effect was previously reported by El-Khateeb et al. ${ }^{11}$ for some hydrolysis products of cisplatin.

So, the objective of the present work was to develop and validate a reversed-phase HPLC procedure with ultraviolet detection for the simultaneous determination of cisplatin and the complex cis, cis,transdiamminedichlorodihydroxoplatinum(IV), in aqueous solutions.

\section{EXPERIMENTAL}

\section{Chemical reagents and solutions}

High-quality products from recognized companies were employed. Unless otherwise specified, they were used without further purification. Cisplatin and sodium chloride $(\mathrm{NaCl})$ were purchased from Aldrich (99.99\%) and hydrogen peroxide $\left(\mathrm{H}_{2} \mathrm{O}_{2}\right) 30 \% \mathrm{v} / \mathrm{v}$ from BDH. Methanesulphonic acid from Fluka (Sigma-Aldrich, St. Louis, MO, USA) was used. Methanol for liquid chromatography was supplied by Merck. Water employed in all experiments was obtained from distilled water, which was ozonized and distilled again immediately before use. 
Standard cis,cis,trans-diamminedichlorodihydroxoplatinum(IV) was synthesized according to the published procedure. ${ }^{12}$ Typically, $100 \mathrm{mg}$ cisplatin in $2 \mathrm{~mL}$ of $\mathrm{H}_{2} \mathrm{O}_{2} 30 \% \mathrm{v} / \mathrm{v}$ was heated on a water bath and maintained at $80{ }^{\circ} \mathrm{C}$ for $150 \mathrm{~min}$. As the oxidation proceeded, cisplatin dissolved and the yellow solution slowly turned to lemon yellow color. Then, the mixture was allowed to cool to room temperature. Yellow precipitate formed was filtered off, washed with ethanol and dried over $\mathrm{P}_{4} \mathrm{O}_{10}$ under vacuum.

Cisplatin and cis, cis,trans-diamminedichlorodihydroxoplatinum(IV) were prepared as stock solutions of $2.5 \times 10^{-3} \mathrm{~mol} \mathrm{~L}^{-1}$ in $0.9 \% \mathrm{NaCl}$ and water, respectively. Standards solutions of lower concentration of both complexes (range, 0.5 to $1.5 \times 10^{-3} \mathrm{~mol} \mathrm{~L}^{-1}$ ) were prepared by diluting stock solutions, in the same solvents.

\section{Identity and purity of the synthesized cis,cis,trans-diamminedi chlorodihydroxoplatinum(IV)}

The identity and purity of the synthesized complex was confirmed by infrared spectroscopy and mass spectrometry. Mass spectrum, in the $\mathrm{m} / \mathrm{z}$ range from 50 to 500 Dalton (Da), was taken in a mass spectrometer with an electrospray ionization (Q-TOF-2 Micromass, UK), operating in the positive ion mode. Capillary and cone voltages were 1200 and $35 \mathrm{~V}$, respectively. The cone temperature was $353 \mathrm{~K}$. To acquire the ESI-MS/MS mass spectrum, the first quadrupole was used to select the precursor ion within about $2 \mathrm{Da}$. Argon was employed in the collision chamber at approximately $3 \times 10^{-2} \mathrm{~Pa}$ and collision energies between 17 and $35 \mathrm{eV}$ were set to fragment precursor ions. Data acquisition and processing were performed by Mass Lynx software version 3.5 (Micromass, Milford, MA, USA). The infrared spectrum was recorded in the $4000-400 \mathrm{~cm}^{-1}$ spectral region by a Jasco FT/IR-460 Plus spectrophotometer (Jasco Instrument. Corp., Japan), using the $\mathrm{KBr}$ technique.

\section{Ozonation system}

Ozonation of non-buffered cisplatin solution $1 \times 10^{-3} \mathrm{~mol} \mathrm{~L}^{-1}$ at $\mathrm{pH} 9$ was performed in a laboratory experimental installation, schematically shown in Figure 2. It consisted of a $100 \mathrm{~mL}$ jacketed glass reactor (semibatch) equipped with a porous glass diffuser, a sample port, a gas inlet and a gas outlet. The reactor off-gas was catalytically destroyed. The reactor was coupled to a thermostat which controlled the temperature at $30 \pm 0.1^{\circ} \mathrm{C}$. The oxygen-ozone mixture was obtained from an ozonator (model AQOZO, CIozono, Cuba). Inlet ozone gas concentration, determined at $256 \mathrm{~nm}$ in a spectrophotometer (Ultrospec III, Pharmacia, UK), was $45 \mathrm{mg} \mathrm{L}^{-1}$ and the gas flow was $5 \mathrm{~L} \mathrm{~h}^{-1}$.
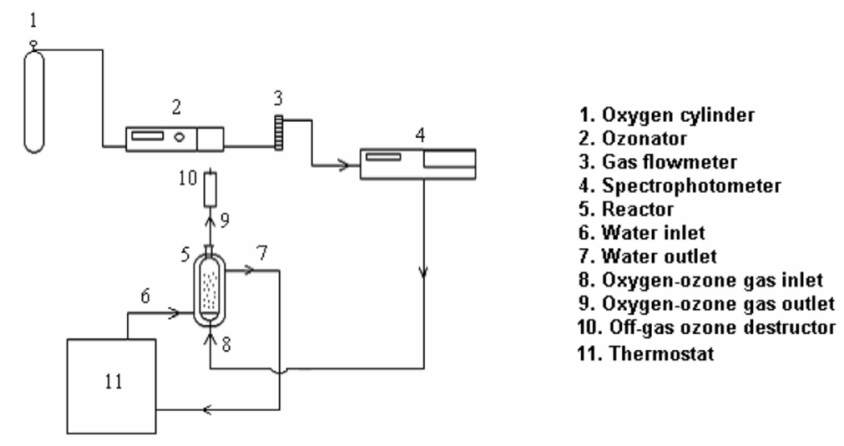

Figure 2. Experimental installation of cisplatin ozonation

At $2 \mathrm{~min}$ of reaction time, $100 \mathrm{~mL}$ of dissolution of cis, cis, transdiamminedichlorodihydroxoplatinum(IV) was obtained. To develop a HPLC procedure for the simultaneous determination of this complex and cisplatin, $0.030 \mathrm{~g}$ of cisplatin was added and dissolved with the aid of a vortex mixer immediately before use.

\section{HPLC analysis}

The analysis of cisplatin and its ozonation product was carried out by employing isocratic reverse phase high-performance liquid chromatography (RP-HPLC). The system was equipped with a LKB 2150 pump (LKB, Bromma, Sweden), an injection valve with $20-\mu \mathrm{L}$ sample loop and a K-2800 UV/Vis photo diode array (PDA) detector (Knauer, Berlin, Germany). Data processing and integration were performed with Eurochrom 2000 software (Knauer, Berlin, Germany). Compounds were separated on a $25 \times 0.4 \mathrm{~cm}, 5-\mu \mathrm{m}$ particle, Spherisorb $\mathrm{NH}_{2}$ column and two mobile phases were employed. The first contained a mixture of methanol-water (3\% v/v) and $\mathrm{pH} 2.5$ adjusted with methanesulphonic acid (procedure I) and the second contained a mixture of methanolwater (7\% v/v) and $\mathrm{pH} 2.5$ adjusted with the same acid (procedure II). All spectrophotometric detections were measurements at $305 \mathrm{~nm}$. Runs

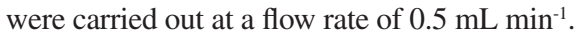

\section{Validation procedures}

The procedure was validated for linearity, accuracy, repeatability of measurement of peak areas and retention times, inter-day precision and selectivity, in accordance with EPA guidelines. ${ }^{13}$

Linearity experiment was performed by using standard solutions of cisplatin and cis,cis,trans-diamminedichlorodihydroxoplatinum(IV) $\left(0.5 ; 0.75 ; 1 ; 1.25\right.$ and $1.5 \times 10^{-3} \mathrm{~mol} \mathrm{~L}^{-1}$, for both complexes). The solutions were injected and peak areas were recorded. The areas of the peaks and the corresponding concentrations were used to construct the plots, using the simple regression method of Statgraphics Plus software.

Limit of detection (LOD) and limit of quantification (LOQ) were calculated as $3.3 \partial /$ (slope of the calibration plot) and $10 \partial /$ (slope of the calibration plot), respectively, where $\partial$ is the standard deviation of the response ( $y$-intercept).

The precision of the assay was determined in terms of repeatability (intra-day) and intermediate (inter-day) precision. Repeatability of measurement of peak area and retention time were determined by analysis of standard solutions of cis,cis,trans-diamminedichlorodihydroxoplatinum(IV) and cisplatin at concentration of $1 \times 10^{-3} \mathrm{~mol}$ $\mathrm{L}^{-1}$, six times on the same day. Inter-day precision was determined by analysis of similar standards on three different days. Coefficient of variation (C.V.) was calculated for both series of analyses.

The accuracy of the HPLC assay procedure was assessed by adding known amount $(15,30$ and $45 \mathrm{mg}$ for cisplatin and 16.7, 33.4 and $50 \mathrm{mg}$ for cis,cis,trans-diamminedichlorodihydroxoplatinum(IV)) of both complexes to a $100 \mathrm{~mL}$ solution of cisplatin and cis, cis,trans-diamminedichlorodihydroxoplatinum(IV) of known concentrations $\left(1 \times 10^{-3} \mathrm{~mol} \mathrm{~L}^{-1}\right)$, in presence of hydrolysis product of cisplatin. Accuracy, as percentage recovery ([mean recovered concentration]/[added concentration] $\times 100$ ), was evaluated at these different levels $\left(0.5 ; 1\right.$ and $1.5 \times 10^{-3} \mathrm{~mol} \mathrm{~L}^{-1}$ for both complexes).

To test the selectivity of the procedure for hydrolysis products of cisplatin, an aqueous solution of cis, cis,trans-diamminedichlorodihydroxoplatinum(IV) and cisplatin, at $\mathrm{pH} 7$ and concentrations of $1 \mathrm{x}$ $10^{-3} \mathrm{~mol} \mathrm{~L}{ }^{-1}$ was prepared. This solution was maintained at $37^{\circ} \mathrm{C}$ for $10 \mathrm{~h}$, protected of the light. After this time, the solution was injected and peak areas of the complexes were recorded. The purity of the peaks was checked by acquisition of UV-VIS spectra (190-600 nm) by use of the PDA detector. Spectra were acquired at the upslope, apex, and downslope of each peak and superimposed.

All experiments were performed in triplicate. 


\section{RESULTS AND DISCUSSION}

For HPLC procedure, chromatographic conditions were established to obtain, an adequate separation of eluted compounds. In the study of Hernández et al..$^{10}$ the separation between cis,cis,transdiamminedichlorodihydroxoplatinum(IV) and cisplatin and was not suitable because a high separation factor value (about 14.1) was obtained. This high value means a run time longer than necessary. The separation factor value depends on such factors as composition of the mobile phase, composition of the stationary phase and temperature. A change in the organic solvent in the mobile phase (e.g. from methanol to acetonitrile) is the first step recommended in developing a new HPLC method. However, acetonitrile is known to interact with platinum complexes, with the formation of the well-known "platinum amide blues" forming as the ultimate products. ${ }^{14}$

For this reason, in this study, a change in the stationary phase was required. Spherisorb $\mathrm{NH}_{2}$ is a polar bonded-phase packing useful in both normal and reversed-phase applications and can be used with highly polar mobile phases such as water/methanol since it is highly stable in water and stable to hydrolysis at low $\mathrm{pH}$.

Separations of cisplatin and its ozonation product were performed on $\mathrm{NH}_{2}$ analytical column with two mobile phases, methanol-water $(3 \% \mathrm{v} / \mathrm{v})$ and $\mathrm{pH}$ adjusted to 2.5 with methanesulphonic acid (procedure I) and methanol-water (7\% v/v) and $\mathrm{pH} 2.5$ adjusted with the same acid (procedure II).

The UV spectra (Figure 3) of cis, cis, trans-diamminedichlorodihydroxoplatinum(IV) and cisplatin in water shows that they have an absorption maximum in the range 200-250 and $305 \mathrm{~nm}$. As 200-250 $\mathrm{nm}$ is very near to the wavelength at which methanol absorbs the UV light, measurements were performed at $305 \mathrm{~nm}$.

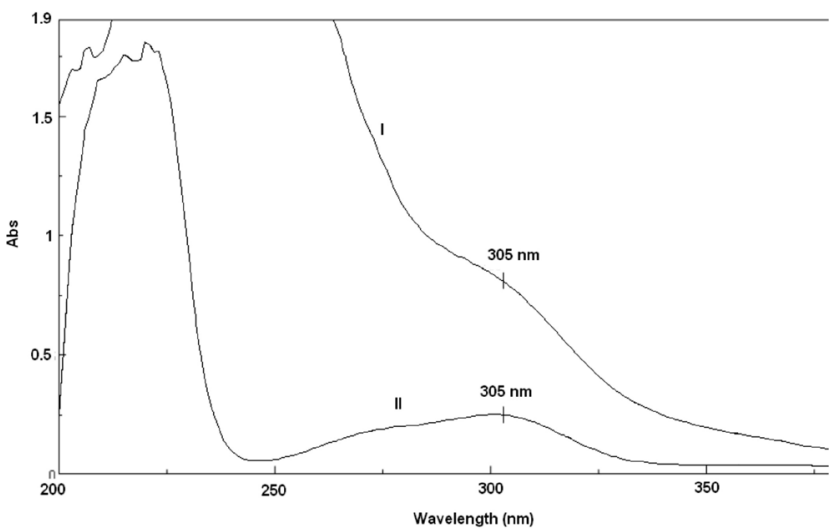

Figure 3. UV spectra of cis, cis, trans-diamminedichlorodihydroxoplatinum( IV) (I) and cisplatin (II) in water

Figure 4a shows typical chromatogram obtained for cisplatin and its ozonation product under the first chromatographic conditions (procedure I). In this case the retention times for cis,cis,trans-diamminedichlorodihydroxoplatinum(IV) (peak 1) and cisplatin (peak 2) were approximately $4.57 \mathrm{~min}(\mathrm{RSD}=0.009 \%)$ and $5.20 \mathrm{~min}(\mathrm{RSD}$ $=0.007 \%$ ), respectively, and the value calculated for the resolution (Rs) was 1.32. Rapid elution of both complexes was observed but the two peaks were only partially separated since a good separation requires more than minimal resolution $(\mathrm{Rs}=1.5)$.

Figure $4 \mathrm{~b}$ shows typical chromatogram obtained for cisplatin and its ozonation products under the second chromatographic conditions (procedure II). In this case the retention times for cis, cis,trans-diamminedichlorodihydroxoplatinum(IV) (peak 1) and cisplatin (peak 2) were approximately $3.45 \mathrm{~min}(\mathrm{RSD}=0.006 \%)$ and $5.28 \mathrm{~min}(\mathrm{RSD}$ $=0.007 \%)$, respectively, and the value calculated for the resolution
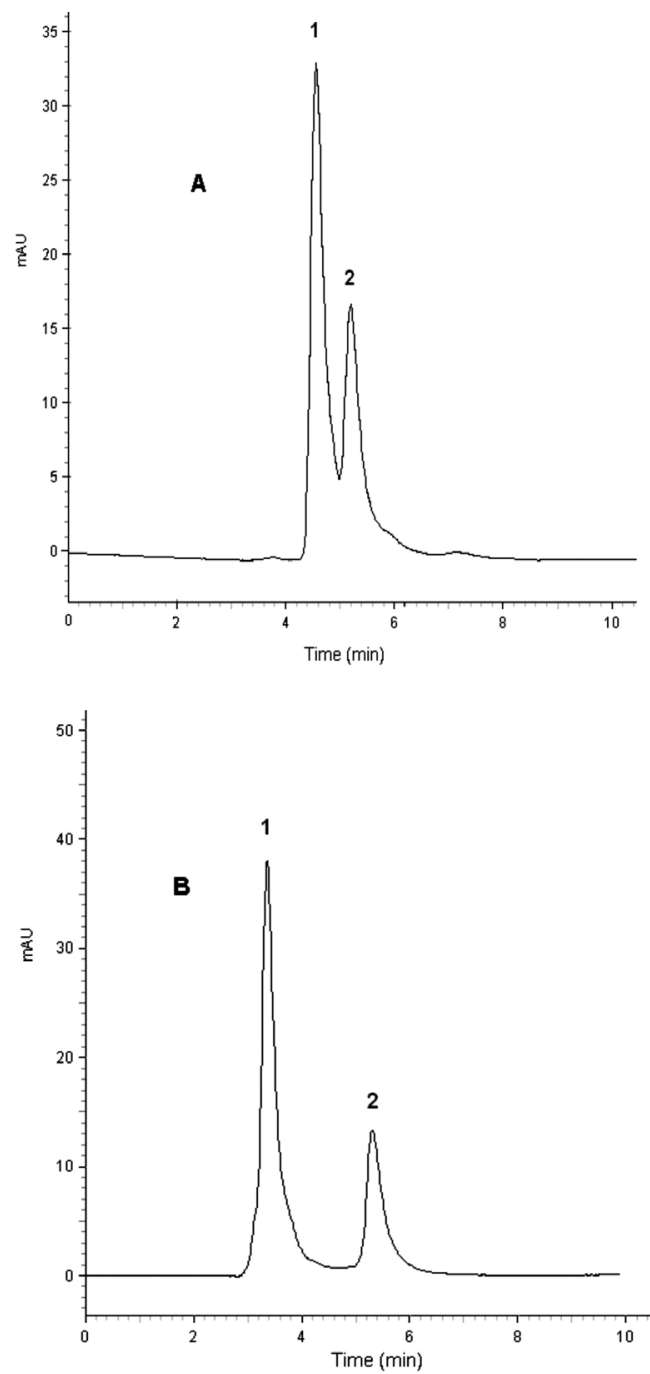

Figure 4. HPLC chromatograms of cisplatin (2) and cis,cis,trans-diammin edichlorodihydroxoplatinum(IV) (1), A: under conditions of procedure I; B: under conditions of procedure II

(Rs) was 3.92. The separation results in rapid elution of both complexes and the two peaks are totally separated (Rs > 1.5).

The results under these two chromatographic conditions show that resolution of the complexes is better in the mobile phase methanol/ water (7\% v/v) and $\mathrm{pH} 2.5$ adjusted with methanesulphonic than in the mobile phase methanol/water $(3 \% \mathrm{v} / \mathrm{v})$ at the same $\mathrm{pH}$ value. Thus, highly efficient separation, reduced analysis time and reduced mobile phase consumption (compared to chromatographic conditions reported by Hernández et al..$^{10}$ ) made the procedure II more suitable for HPLC analysis of cisplatin and its ozonation product, the complex cis,cis,trans-diamminedichlorodihydroxoplatinum(IV).

Nowadays, shorter columns of about $5 \mathrm{~cm}$ or less, also with lower diameter of particle ( $3 \mu \mathrm{m}$ or less) are commonly used. Nevertheless, for the study of cisplatin, the columns of $25 \mathrm{~cm}$ had been employed. ${ }^{15-17}$ For larger operations, shorter columns can be used to reduce the retention time of the compounds, while Rs in not significantly affected. In this study, the use of a shorter column is not necessary because an acceptable run time of analysis is obtained ( $<6 \mathrm{~min})$.

\section{Results from validation}

To carry out the procedure validation study, standard cis, cis,transdiamminedichlorodihydroxoplatinum(IV) was synthesized according 
to the published procedure. ${ }^{12}$ Infrared spectroscopy and mass spectrometry were employed for confirm the identity of this complex.

In the IR spectrum of cis, cis,trans-diamminedichlorodihydroxoplatinum(IV), a strong band at $3512 \mathrm{~cm}^{-1}$, assigned to $\mathrm{PtO}-\mathrm{H}$ stretching vibration, was observed. The coordination of the $\mathrm{OH}$ ligand in the complex is also observed with the presence of two bands at $1041 \mathrm{~cm}^{-1}$ (bending $\delta_{\mathrm{Pt}-\mathrm{OH}}$ ) and $554 \mathrm{~cm}^{-1}$ (stretching $\mathrm{v}_{\mathrm{Pt}-\mathrm{O}}$ ). The bands at 1360 and $1300 \mathrm{~cm}^{-1}$ are due to $\mathrm{O}-\mathrm{H}$ bending vibrations and the bands at 3258 and $456 \mathrm{~cm}^{-1}$ are due to PtN-H and Pt-N stretching vibrations, respectively. These results are in concordance with previously published studies of platinum(II) and platinum(IV) complexes. ${ }^{18,19}$

In the case of platinum complexes, due to the isotopes of platinum $\left({ }^{194} \mathrm{Pt},{ }^{195} \mathrm{Pt},{ }^{196} \mathrm{Pt}\right)$ and chloride $\left({ }^{35} \mathrm{Cl}\right.$ and $\left.{ }^{37} \mathrm{Cl}\right)$, the ESI mass spectra exhibit a characteristic cluster patter. In the mass spectrum of the synthesized product, the most intensive mass peak at $\mathrm{m} / \mathrm{z} 335$ was obtained. Consistent with the ion mass, the structure was proposed to be $\left.\mathrm{Pt}\left(\mathrm{NH}_{3}\right)_{2}(\mathrm{OH})_{2}(\mathrm{Cl})_{2}\right]^{\mathrm{H}+}$. The theoretical isotope cluster of the complex $\left.\mathrm{Pt}\left(\mathrm{NH}_{3}\right)_{2}(\mathrm{OH})_{2}(\mathrm{Cl})_{2}\right]^{\mathrm{H}+}$ was in good agreement with the experimental isotope cluster.

To further support this finding, tandem mass spectrometry was employed. MS/MS at $\mathrm{m} / z, 335$ ion gave rise to the main fragment ion at $m / z, 317\left(\left[\mathrm{M}-\mathrm{H}_{2} \mathrm{O}\right]^{+}\right)$by the loss of $18 \mathrm{Da}$. The ion at $\mathrm{m} / z, 317$ further yielded the ions at $m / z, 299\left(\left[\mathrm{M}-\mathrm{H}_{2} \mathrm{O}-\mathrm{H}_{2} \mathrm{O}\right]^{+}\right)$and $m / z, 281\left(\left[\mathrm{M}-\mathrm{H}_{2} \mathrm{O}-\right.\right.$ $\mathrm{HCl}]^{+}$), by the loss of 18 and $36 \mathrm{Da}$, respectively. These consecutive fragmentations of $18 \mathrm{Da}$, confirms the presence of two $\mathrm{OH}$ ligands in the complex. Finally, the ion at $m / z, 299$ continued to produce the ion at $\mathrm{m} / \mathrm{z}, 263\left(\left[\mathrm{M}-\mathrm{H}_{2} \mathrm{O}-\mathrm{H}_{2} \mathrm{O}-\mathrm{HCl}\right]^{+}\right)$by the loss of $36 \mathrm{Da}$. An identical ESI mass spectrum of cisplatin ozonation product at initial $\mathrm{pH} 9$ was obtained by Hernández et al.. ${ }^{10}$ This result confirm that the synthesized standard cis,cis,trans-diamminedichlorodihydroxoplatinum(IV) is the same that the ozonation product obtained by Hernández et al.. ${ }^{10}$

Results for the determination of linearity, LOD, LOQ, repeatability and inter-day precision are summarized in Table 1.

Table 1. Summary of validation data

\begin{tabular}{lcc}
\hline Procedure characteristic & Cisplatin & $\begin{array}{c}\text { Ozonation } \\
\text { product }\end{array}$ \\
\hline Linear range $\left(\times 10^{-3} \mathrm{~mol} \mathrm{~L}^{-1}\right)$ & $0.5-1.5$ & $0.5-1.5$ \\
Correlation coefficient $(\mathrm{r})$ & 0.9991 & 0.9990 \\
Slope & $3.71 \times 10^{8}$ & $1.15 \times 10^{9}$ \\
y-intercept & 20259.9 & 83046.3 \\
Standard deviation $(\mathrm{n}=3)$ & 5824 & 18470 \\
LOD $\left(\mathrm{x} 10^{-4}\right.$ mol L $\left.{ }^{-1}\right)$ & 0.47 & 0.53 \\
LOQ $\left(x 10^{-4}\right.$ mol L $\left.{ }^{-1}\right)$ & 1.57 & 1.75 \\
Accuracy $(\%$ Rec., $\mathrm{n}=6)$ & $100.6 \pm 1.4$ & $101.2 \pm 1.1$ \\
Repeatability of measurement of peak & 0.66 & 0.47 \\
area $(\mathrm{CV}, \%, \mathrm{n}=6)$ & & 0.18 \\
Repeatability of measurement of & 0.14 & 0.97 \\
retention time $(\mathrm{CV}, \%, \mathrm{n}=6)$ & & 0.89 \\
Inter-day precision $(\mathrm{CV}, \%, \mathrm{n}=6)$ &
\end{tabular}

Linear least-squares regression analysis showed a good linear relationship between peak areas and concentrations of cisplatin and cis,cis,trans-diamminedichlorodihydroxoplatinum(IV) in the range $0.5-1.5 \times 10^{-3} \mathrm{~mol} \mathrm{~L}^{-1}(\mathrm{r} \geq 0.999)$.

The LOD, expressed as $3.3 \sigma /$ (slope of the calibration plot), was found to be $0.53 \times 10^{-4}$ and $0.47 \times 10^{-4} \mathrm{~mol} \mathrm{~L}^{-1}$ for cis,cis,trans-diamminedichlorodihydroxoplatinum(IV) and cisplatin, respectively. LOQ, expressed as $10 \sigma /$ (slope of the calibration plot), was found to be $1.75 \times 10^{-4}$ and $1.57 \times 10^{-4} \mathrm{~mol} \mathrm{~L}^{-1}$, for cis, cis,trans-diamminedichlorodihydroxoplatinum(IV) and cisplatin, respectively. A deficiency of this procedure is that the LOD and LOQ are higher than previ- ously reported in the literature. In these cases more sensitive detection methods, such as ICP-MS ${ }^{5,20,21}$ and ESI-MS, ${ }^{22}$ were employed. To solve this problem, a preconcentration step should be included in the analysis in order to determine lower concentrations of these compounds. ${ }^{23}$ Nevertheless, this analytical procedure can be used to detect these compounds in water because in previously studies, concentrations of complexes of platinum(II) and platinum(IV) in water and wastewaters, over the quantification limits of this analytical procedure, have been reported. ${ }^{24,25}$

Inter-day precision expressed as coefficient of variation $(\mathrm{CV}, \%)$ were 0.89 and $0.97 \%$, for cisplatin and cis,cis,trans-diamminedichlorodihydroxoplatinum(IV), respectively. The repeatability of the procedure was demonstrated by measuring the retention times and peak areas of cisplatin and cis,cis,trans-diamminedichlorodihydrox oplatinum(IV). In both cases the coefficients of variation were $<1$. These small values indicated the procedure is precise.

The accuracy of the procedure was determined by recovery experiments. The recovery studies were carried out 6 times and the percentage recovery was calculated. From the data obtained, recoveries of standard complexes were found to be accurate (Table 2 ), because values near to $100 \%$ were obtained for both complexes.

Table 2. Recovery of cis, cis, trans-diamminedichlorodihydroxoplatinum(IV) and cisplatin

\begin{tabular}{lccc}
\hline Complex & $\begin{array}{c}\text { Amount added }(\mathrm{x} \\
\left.10^{-3} \mathrm{~mol} \mathrm{~L}^{-1}\right)\end{array}$ & $\begin{array}{c}\text { Amount } \\
\text { recovered } \\
\left(\mathrm{x} 10^{-3} \mathrm{~mol} \mathrm{~L}^{-1}\right)\end{array}$ & Recovery $(\%)^{\mathrm{a}}$ \\
\hline Cisplatin & 0.5 & 0.49 & $98.0 \pm 0.9$ \\
& 1.0 & 1.03 & $103.0 \pm 1.8$ \\
Ozonation product & 1.5 & 1.51 & $100.7 \pm 1.4$ \\
& 0.5 & 0.51 & $102.0 \pm 1.1$ \\
& 1.0 & 1.02 & $103.0 \pm 1.5$ \\
& 1.5 & 1.48 & $98.7 \pm 0.6$ \\
\hline
\end{tabular}

Specificity is the ability to unequivocally assess an analyte in the presence of other components in the simple matrix, such as impurities and degradation products.

In a $0.9 \% \mathrm{NaCl}$ solution, cisplatin was stable for $24 \mathrm{~h}$ at room temperature and protected of the light. Nevertheless, in aqueous solution

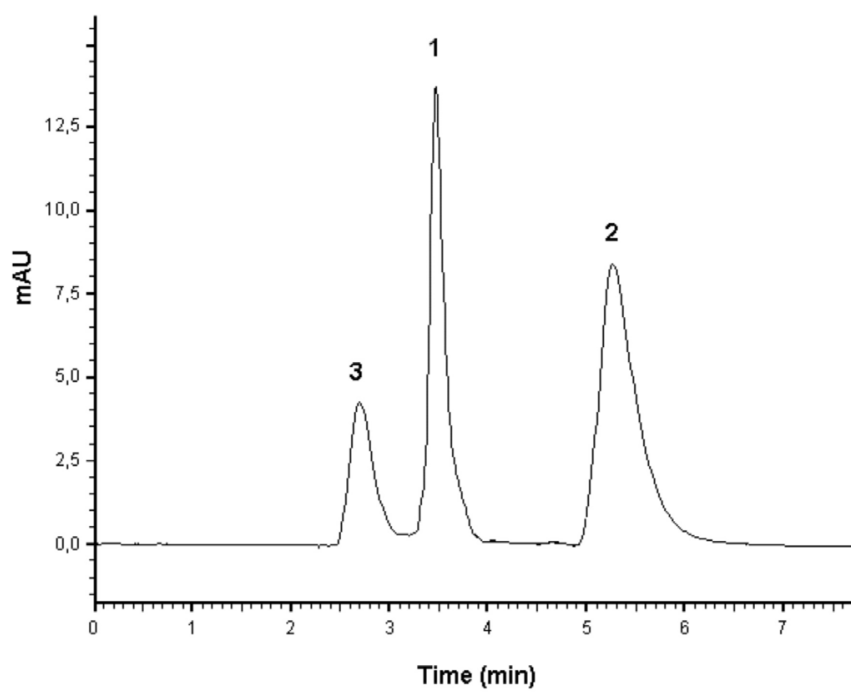

Figure 5. HPLC chromatogram of cisplatin and cis,cis,trans-diamminedichlor odihydroxoplatinum(IV) maintained at $37^{\circ} \mathrm{C}$ during $10 \mathrm{~h}$ in aqueous solution. Peaks: 3: hydrated complex Pt(II), $t_{R 3}=2.68 \mathrm{~min} ; 1$ : cis, cis,trans-diammin edichlorodihydroxoplatinum $(I V), t_{R 1}=3.45 \mathrm{~min} ; 2$ : cisplatin, $t_{R 2}=5.27 \mathrm{~min}$ 
the chloride ions in cisplatin are easily exchange with water molecules to form the complexes $\left[\mathrm{Pt}\left(\mathrm{NH}_{3}\right)_{2}\left(\mathrm{H}_{2} \mathrm{O}\right) \mathrm{Cl}\right]$ and/or $\left[\mathrm{Pt}\left(\mathrm{NH}_{3}\right)_{2}\left(\mathrm{H}_{2} \mathrm{O}\right)_{2}\right]$. At pH 7 the complex $\left[\mathrm{Pt}\left(\mathrm{NH}_{3}\right)_{2}\left(\mathrm{H}_{2} \mathrm{O}\right) \mathrm{Cl}\right]$ is the dominating after about $10 \mathrm{~h}$ and remains as the major specie during $40 \mathrm{~h}^{26}$

The specificity of the procedure is illustrated in Figure 5, which shows complete separation of cisplatin and cis,cis,trans-diamminedichlorodihydroxoplatinum(IV) in presence of hydrolysis product of cisplatin. Although the peak corresponding to the hydrolysis product (retention time $=2.68 \mathrm{~min}$ ) cannot be identify it is reasonable that the peak corresponding to the complex $\left[\mathrm{Pt}\left(\mathrm{NH}_{3}\right)_{2}\left(\mathrm{H}_{2} \mathrm{O}\right) \mathrm{Cl}\right]$.

In peak purity analyses of cis,cis,trans-diamminedichlorodihydroxoplatinum(IV) and cisplatin with PDA, the spectra obtained at the beginning, middle and end of the bands did not differ significantly. This shows that the peaks of analytes were pure and the hydrolysis product of cisplatin does not interfere in the analysis.

\section{CONCLUSIONS}

An isocratic procedure for the RP-HPLC separation of cisplatin and the complex cis,cis,trans-diamminedichlorodihydroxoplatinum(IV) was developed. The procedure is rapid, simple, repeatable, linear, precise, accurate and specific for hydrolysis products of cisplatin. The proposed procedure was used for the simultaneous determination of cisplatin and cis, cis,trans-diamminedichlorodihyd roxoplatinum(IV), in aqueous solutions.

\section{REFERENCES}

1. IARC Monographs on the Evaluation of the Carcinogenic Risk of Chemicals to Man. Overall evaluations of carcinogenicity, International Agency for Research on Cancer: Lyon, 1987, vol. 7, p. 60.

2. Yamamoto, H.; Hayashi, A.; Nakamura, Y.; Sekizawa, J.; J. Environ. Sci. 2005, 12, 347.

3. Jasim, S. Y.; Irabelli, A.; Yang, P.; Ahmed, S.; Schweitzer, L.; Ozone-Sci. Eng. 2006, 28, 415.

4. Mauricio, R.; Diniz, M.; Petrovic, M.; Amaral, L.; Peres, I.; Barceló, D.; Santana, F.; Environ. Monit. Assess. 2006, 118, 75.

5. Hann, S.; Stefanka, Z.; Lenz, K.; Stingeder, G.; Anal. Bioanal. Chem. 2005, 381, 405 .
6. Fuerhacker, M.; Mahnik, S. N.; Lenz, K.; Weissenbacher, N.; Mader, R. W.; Krenn, P.; Hann, S.; Koellensperger, G.; Knasmüller, S.; Ferk, F.; Uhl, M.; Bursch, W.; Proceedings of $3^{\text {rd }}$ SWIFT-WFD, Barcelona, Spain, 2006.

7. Lenz, K.; Mahnik, S. N.; Weissenbacher, N.; Mader, R. W.; Krenn, P.; Hann, S.; Koellensperger, G.; Uhl, M.; Knasmüller, S.; Ferk, F.; Bursch, W.; Fuerhacker, M.; Water Sci. Technol. 2007, 56, 141.

8. Lenz, K.; Koellensperger, G.; Hann, S.; Weissenbacher, N.; Mahnik, S. N.; Fuerhacker, M.; Chemosphere 2007, 69, 1765.

9. Heberer, T.; Toxicol. Lett. 2002, 131, 5.

10. Hernández, C.; Ramos, Y.; Fernández, L. A.; Ledea, O.; Bataller, M.; Véliz, E.; Besada, V.; Rosado, A.; Ozone-Sci. Eng. 2008, 30, 189.

11. El-Khateeb, M.; Appleton, T. G.; Charles, B. G.; Gahan, L. R.; J. Pharm. Sci. 1999, 88, 319.

12. Weave, E. L.; Bose, R. N.; J. Inorg. Biochem. 2003, 95, 231.

13. Mishalanie, E. A.; Lesnik, B.; Araki, R.; Segall, R.; Validation and Peer Review of U.S. Environmental Protection Agency Chemical Methods of Analysis, EPA Forum on Environmental Measurements (FEM), 2005.

14. Gillard, R. D.; Wilkinson, G.; J. Chem. Soc. 1964, 2835.

15. Haraguchi, H.; Ohshima, T.; Matsuura, H.; Hasegawa, T.; Anal. Sci. 2001, 17, 137.

16. Dabrowiak, J. C.; Goodisman, J.; Sovid, A.; Drug Metab. Dispos. 2002, 30, 1378 .

17. Towsend, D.; Marto, J.; Deng, M.; Macdonald, T. J.; Hanigan, M. H.; Drug Metab. Dispos. 2003, 31, 705.

18. Michalska, D.; Wysokinski, R.; Hernik, K.; Szostak, R.; Chem. Phys. 2007, 333, 37.

19. Soo Sohn, Y.; Ju Lee, E.; Korean Chem. Soc. 1999, 20, 1295.

20. Hann, S.; Koellensperger, G.; Stefánka, Z.; Stingeder, W.; Fürhacker, M.; Buchberger, W.; Mader, R. M.; J. Anal. At. Spectrom. 2003, 18, 1391.

21. Brouwers, E. M.; Tibben, M.; Rosing, H.; Schellens, J.; Beijnen, J. H.; Mass Spectrom. Rev. 2008, 27, 67.

22. Cui, M.; Mester, Z.; Rapid Commun. Mass Spectrom. 2003, 17, 1517.

23. Raghavan, R.; Burchett, M.; Loffredo, D.; Mulligan, J. A.; Drug Dev. Ind. Pharm. 2000, 26, 429.

24. Wook, W. S.; Mao, J.; In-Seob, K. M.; Yun, Y. S.; Bioresour. Technol. 2010, 101, 1135.

25. Rashamuse, K. J.; Mutambanengwe, C. C.; Whiteley, C. G.; Afr. J. Biotechnol. 2008, 7, 1087.

26. Vinje, J.; Sletten, E.; Anti-cancer Agents Med. Chem. 2007, 7, 35. 